\title{
Tracking System for Indoor TV Antenna Based on CVBS Signal Processing
}

\author{
Herti Miawarni $^{\text {a,* }}$, M. Mahaputra Hidayat ${ }^{a}$, Surya Sumpeno ${ }^{b}$, Eko Setijadi ${ }^{b}$ \\ ${ }^{a}$ Departement of Engineering Faculty \\ Bhayangkara Surabaya University \\ Jl. Ahmad Yani 114 - 60231 \\ Surabaya, Indonesia \\ ${ }^{b}$ Departement of Electrical Engineering \\ Institut Teknologi Sepuluh Nopember (ITS) \\ Jl. Arief Rahman Hakim, Kampus Keputih, Sukolilo - 60111 \\ Surabaya, Indonesia
}

\begin{abstract}
Analog terrestrial TV is still a popular choice for urban societies although the migration to digital system has already begun. Video quality of analog TV was heavily influenced by antenna performance. Most users prefer to use indoor antenna due to its simplicity. The disadvantage of this type of antenna is the users may need to change the antenna direction repeatedly when they change to different TV channel. In this research, we designed and developed tracking system that enables indoor TV antenna to adjust its direction automatically to get optimum video clarity. This system is built by several servo motors and telescopic antennas. Composite Video Baseband Signal (CVBS) processing is used to obtain reference information regarding video clarity level conditions on TV screen. The results show that CVBS signal processing has performance in describing video clarity level. System performance has been verified from trial results on some UHF channels. The minimum tracking time was 23.4 seconds and the maximum tracking time was 24.6 seconds.
\end{abstract}

Keywords: antenna tracking system, analog TV, telescopic antenna, servo motor, CVBS signal.

\section{INTRODUCTION}

Television has become an essential device in our daily life as a source of information and entertainment. To date, television broadcasting typically uses an analog system. Even though television broadcasting system already began to migrate to a digital system [1], most of the TV consumers still continue to use the existing analog TV devices.

The quality and clarity of video on analog TV broadcast depends on the environment. With the fact that TV signals are highly directional, the antenna should be pointed precisely at the transmitting antenna to get the strongest received signal. Using an outdoor antenna brings better video clarity. However, the establishment and adjustment of such an outdoor antenna are difficult. Thus, many users prefer to use indoor antenna that is certainly more practical physically and the position can be set anytime. Telescopic antenna is one of the many types of indoor TV antenna that is often used by society. The advantages of this antenna are lightweight, cheap and has a lot of angle variations. Telescopic Antenna was proposed for portable DVB-T TV [2] - [3].

Although indoor antenna is easy to use, the antenna direction and the receiving angle may need to be manually adjusted by the user. If the user wants to

\footnotetext{
* Corresponding Author.

Email: hertimia@ubhara.ac.id

Received: October 10, 2017 ; Revised: December 21, 2017

Accepted: December 27, 2017 ; Published: December 30, 2017

(C) 2017 PPET - LIPI
}

watch other TV program, then the antenna adjustment must be repeated. In our previous work [4], an antenna tracking system that automatically rotates antenna direction to get optimum video clarity had been developed. Servo motors were used as antenna rotators. In [5], Servo motors are used in the tracking antenna system for satellite TV reception on boats. Furthermore, in [6], servo motors have also been employed for characteristic configuration of antennas radiation pattern.

For the case of analog $\mathrm{TV}$, the information regarding video clarity level can be utilized as reference parameters for antenna tracking system. Video clarity information can be obtained from the comparison of luminance and chrominance signals to noise [7], using mathematical analysis like MSE (Mean Squared Error) and PSNR (Peak Signal-to-Noise Ratio) as fidelity metrics [8], or using mathematical analysis like Sobel filtering, Laplace filtering, fast Fourier transforms [9]. However, all of the previous proposed methods are highly complex in process. In [4], [10] - [12], Composite Video Baseband Signal (CVBS) is used to obtain video clarity information by calculating rising transition between synchronization level and blanking level. This method is simple and can be applied to microcontroller with low computational capability. CVBS signal usually available on the TV rear panel, particularly on the AV-Out connection.

The purpose of this research is to develop tracking system for indoor TV antenna. Telescopic antenna is used for analog TV receiver. Different from previous 
experimental setting in [4] where the elevation and azimuth angle of the antenna were changed according to the angular change of the servo motor, in this research, the rotation of the antenna azimuth angle is restricted. In [4], CVBS signal processing results can describe the video clarity level on the user's TV screen. Even so, the CVBS signal processing is still too simple and needs improvement. The CVBS signal processing results are then developed for real time VQA (Video Quality Assessment) [10]. The CVBS signal processing results have been developed with the approach of visual perception [11]. The CVBS signal processing has also been developed in terms of hardware support [12]. In this research, we combine the results of previous research [4], [10] - [12] and then apply them on tracking antenna system as a completed prototype. The controller circuit is designed, so that the antenna can rotate and change direction until the video clarity level on the TV screen is optimized. Decision-making process on the tracking antenna system is not derived from the results of electromagnetic field analysis, but derived from CVBS signal processing results.

\section{METHODOLOGY}

Efforts to build tracking antenna system are conducted through 4 steps. In general, the research methodology can be visualized in Figure 1. The first step is related to mechanical design, which includes antenna construction and servo motor as antenna rotator. The second step is related to hardware design consisting of electronics circuit design for CVBS signal processing, microcontroller and driver motor. The third step is related to the algorithm design that consists of signal processing algorithms, real-time VQA and decision making process. In general, block diagram of tracking antenna system design shows on Figure 2.

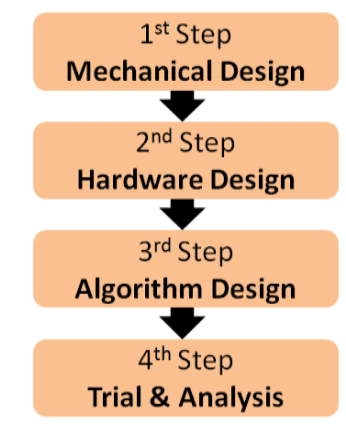

Figure 1. Research methodology.

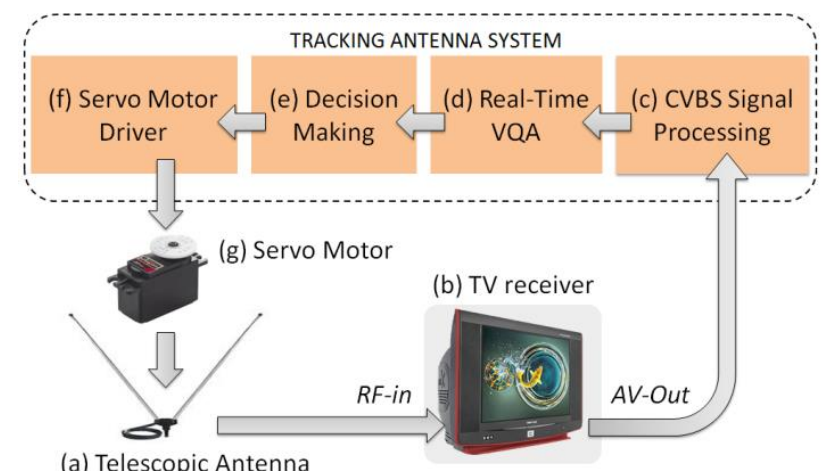

Figure 2. Antenna tracking system. follows:

The proposed antenna tracking system works as

a) Telescopic antenna as a typical television antenna for TV receiver connected to the RF-in (Antenna in) connection on the TV rear panel. Simultaneously, AV-Out connection will produce CVBS signal.

b) CVBS signal processing block is used to process CVBS signal and aims to get video clarity level information on TV screen. Processing output is a numerical value that can change according to the video clarity level on the TV screen. In this research, numerical value is initialized with $R t$ variable. CVBS signal processing will be discussed on sub section Hardware Design especially sub section $B 1$.

c) Real time VQA (Video Quality Assessment) block serves to assess the quality of video in real-time. This block converts the numerical value of CVBS signal processing result into descriptive information. The descriptive information is classified into 5 quality scales that define the visual perception ("good clarity", "fairly clarity", "bad clarity", "worst clarity" and "noisy"). Real time VQA will be discussed on sub section "Algorithm Design" especially sub section $C 2$.

d) Decision-making used to determine the direction of antenna, tracking command and idle command. The descriptive information of the real-time VQA results is used as a reference in the decision making process. The output of the decision making process is a command in PWM signal (Pulse Width Modulation) to control the servo motor.

e) Servo motor driver block serves as the interface between servo motor and microcontroller.

f) Servo motor as a rotator antenna serves to change the direction of the antenna. Servo motor will rotate according to PWM signal. The rotation of servo motor will affect to the direction of the antenna.

\section{A. Mechanical Design}

\section{1) Telescopic Antenna}

Telescopic antenna type in this work is the rabbit ears or the bunny ears antenna, which is the oldest and most widely used indoor TV antenna models. This antenna is made of two telescopic rods and is classified as dipole antenna. Figure 3 shows the physical form of this antenna.

The length of the antenna is determined by considering the frequency and channel of the TV broadcast. In urban area, particularly Surabaya city, analog television broadcast channel starts at 9 VHF to $62 \mathrm{UHF}$ or at carrier frequency $210.25 \mathrm{MHz}$ to 799.25 $\mathrm{MHz}$. On the system design, the length of the antenna element is adjusted to the middle channel 36 UHF or at carrier frequency 591.25. The rods length of the antenna

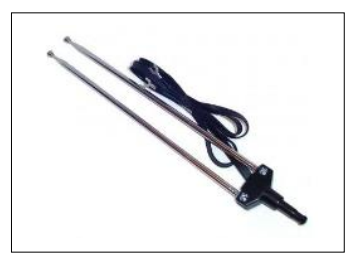

Figure 3. Telescopic antenna 
element is determined by rule $\lambda=\left(3 \times 10^{8}\right) /$ frequency, thus, the rods length of $\frac{1}{2} \lambda$ is $0.254 \mathrm{~m}$ or $25.4 \mathrm{~cm}$.

\section{2) Servo Motors}

The antenna tracking system uses 3 servo motors. Each of the two telescopic rods is connected to 2 servo motor shafts. Meanwhile, the other servo motor serves to rotate two telescopic rods together at azimuth angle. Figure 4 shows the photograph of the antenna tracking system.

\section{B. Hardware Design}

In term of hardware design, tracking antenna system consists of CVBS signal processing circuits, ATMega 32-A microcontroller circuits, Arduino UNO board, Servo motors driver circuits, and 3 servo motors. Figure 5 shows the complete hardware design.

\section{1) CVBS Signal Processing Circuits}

CVBS (Composite Video Baseband Signal) or socalled with Composite Video is an analog video interface that contains a combination of luminance signals (black and white), chrominance signals (color), burst signals, and synchronization on single cable [13].

The working principle of CVBS signal processing in this research is by counting the synchronization pulse on the CVBS (Composite Video Baseband Signal) that is performed by calculating rising transition between synchronization level and blanking level. Figure 6 shows the rising transition. In this research, rising transition is initialized as $R t$ variable.

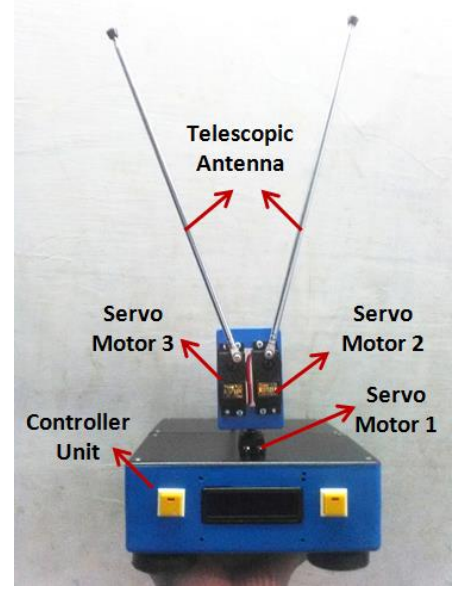

Figure 4. Mechanical design

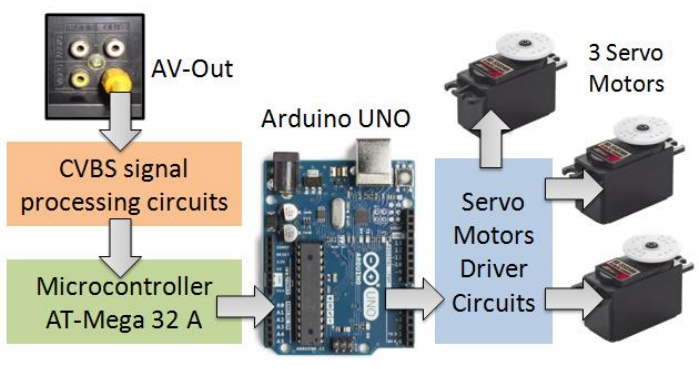

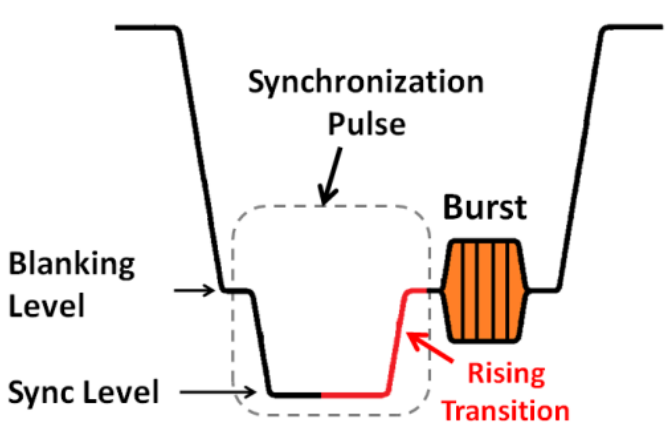

Figure 6. Rising transition of CVBS signal

In Indonesia, the color encoding standard that used for analog television is PAL (Phase Alternating Line). PAL B for VHF channel and PAL G for UHF channel. On the PAL B and G standard, the number of lines is 15,625 per second, the number of frames (images) are 25 per second and each frame has 2 fields (odd and even). The number of rising transition on the synchronization pulse as a whole amounts to 640 per frame. This value is derived from the summing transition from each line. If there are 25 frames for every second, then the rising transition number is 16,000 per second. If the video clarity is optimized, then the value of $R t$ variable will be close to 16,000 . Vice versa, if the video clarity level becomes worse, then the value of $R t$ variable will be closer to zero. This is because, when the clarity level gets worse, the synchronization pulse cannot be detected so it cannot be calculated by the system.

In the implementation, synchronization pulse on the CVBS signal cannot be precisely calculated. Synchronization pulse must first be separated from other signals (luminance signal and chrominance signal). After separated, the voltage level on the synchronization pulse must be adjusted to the required voltage level required by the microcontroller. Figure 7 shows the design of the CVBS signal processing circuit.

LM $1881 \mathrm{~N}$ is an integrated circuit that serves as sync separator. Sync separator is used to separate the synchronization pulse from CVBS signal. IC LM 1881 $\mathrm{N}$ provides 4 output include composite sync output, vertical sync output, odd/even output and burst output. However, in this research, only composite sync output is used. Figure 8 shows the characteristics of IC LM 1881 $\mathrm{N}$ output [14].

Analog comparator is the simplest Analog to Digital Converter (ADC) circuit. Composite sync output on IC LM $1881 \mathrm{~N}$ has various voltage levels according to the video clarity level. Meanwhile, the interrupt pin on the microcontroller is only compatible with digital logic. Interrupt pin and timer counter on the microcontroller are used to count the synchronization pulse. Therefore, the analog comparator is used to ensure that IC LM $1881 \mathrm{~N}$ output signal level can always be read by interrupt pin on the microcontroller.

Figure 5. Hardware design 


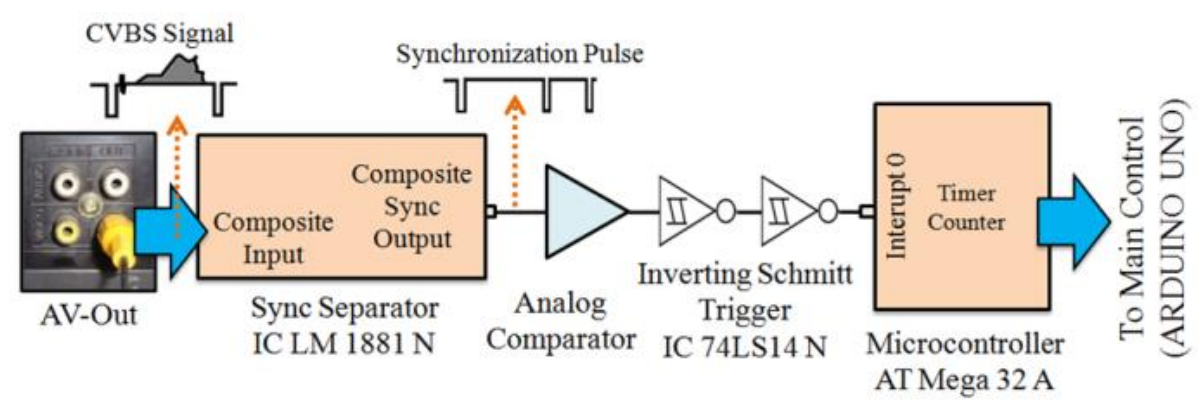

Figure 7. Design of the CVBS signal processing circuits

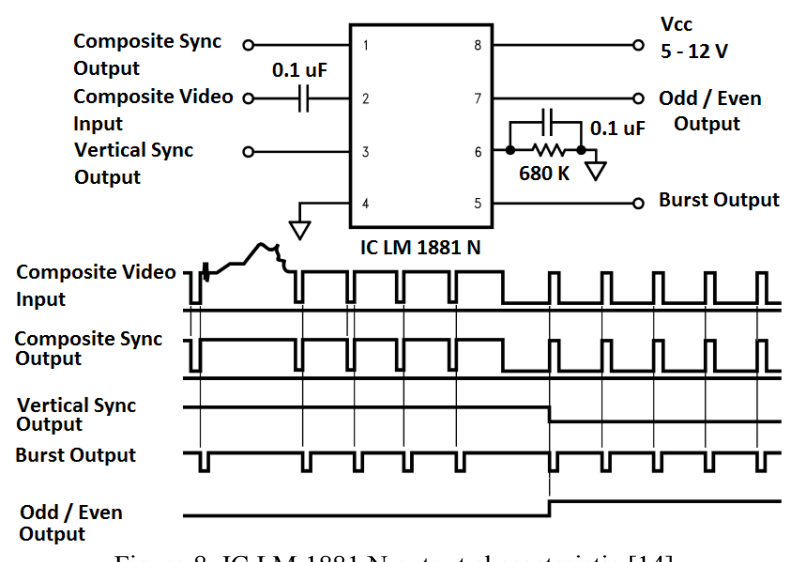

Figure 8. IC LM $1881 \mathrm{~N}$ output characteristic [14]

The synchronization pulses of CVBS signal have a rise time. In addition, CVBS signals on the AV-Out also contains noise especially when TV signal is dominated by noise or ghosting. Therefore, the inverting Schmitt trigger that is arranged in series is used in this research. First, inverter gate is used to reduce the rise time and noise effect. Then, second inverter gate is used to invert the logic conditions to be equal to the composite sync output logic.

\section{2) Microcontroller}

In term of processor, the tracking antenna system requires a lot of timer function on the microcontroller. In order for the system to run smoothly, the tracking antenna system uses 2 microcontrollers. The first microcontroller is AT-Mega 32A that serves as a slave and focuses on real time VQA handling. Meanwhile, the second microcontroller is Arduino UNO that serves as master and focused to set PWM (Pulse Width Modulation) servo motor and the decision making.

\section{Algorithm Design}

\section{1) CVBS Signal Processing Algorithm}

This algorithm is written in listing program of timer counter function on the microcontroller AT-Mega 32A, which serves to calculate the number of synchronization pulses every second in real-time. The calculated result is acquired as the value of $R t$ variable.

\section{2) Real-Time VQA using MOS-VQS}

Real-time VQA (Video Quality Assessment) is the VQA process that works in real-time on every second. Video quality assessment or video quality metric is used to perceive image and video quality automatically. Especially, video clarity on TV screen.

Although the value of $R t$ variable may describe the video clarity level on the television screen, it cannot describe the visual perception as user perception [9]. The $R t$ variable value requires further processing, so that it can be used as accurate information regarding the video clarity level on the television screen. Therefore, the input of the real-time VQA is the value of $R t$ variable.

There are several methods that can be used to build VQA. One of the many methods is the MOS-VQS approach (Mean Opinion Score - Video Quality Subjective). In a previous research, the MOS approach was once used to assess the video clarity level in Analog TV reception [7], [11].

MOS-VQS is a visual perception approach recommendation from ITU-T (International Telecommunication Union - Telecommunication standard section). MOS-VQS is used to assess the quality of the video subjectively. The subjectivity in this case is to assess the quality of the video based on its clarity only. Particularly, the video clarity level on analog TV reception is heavily influenced by noise and ghosting. MOS-VQS generally uses 5 points quality scale, i.e. excellent, good, fair, poor and bad [15]. However, in this research, 5 points of MOS quality scale were initialized as video clarity levels on TV screens: "good clarity", "fairly clarity", "bad clarity", "worst clarity", "noisy". Then, 5 video clarity level conditions on the TV screen are subjectively classified as shown in Table 1. This classification is based on the analog TV reception characteristics of the urban areas, of which ghosting or multipath noise is generally the main problem.

The output of real-time VQA is information related to the video clarity level on the TV screen. This information will be presented as an integer between 1 to $5(1 \geq$ VQA Out $\leq 5)$. VQA Out is equal to 5 if the video clarity level on the TV screen is in good clarity condition, VQA Out is equal to 4 if the video clarity level on TV screen is in fairly clear condition, and so on. This information is sent in bit signals from the microcontroller pin of AT-Mega 32A to the microcontroller pin of Arduino UNO. 
TABLE 1

SuBJECTIVELY VIDEO CLARITY LEVEL CLASSIFICATION WITH MOS-VQS

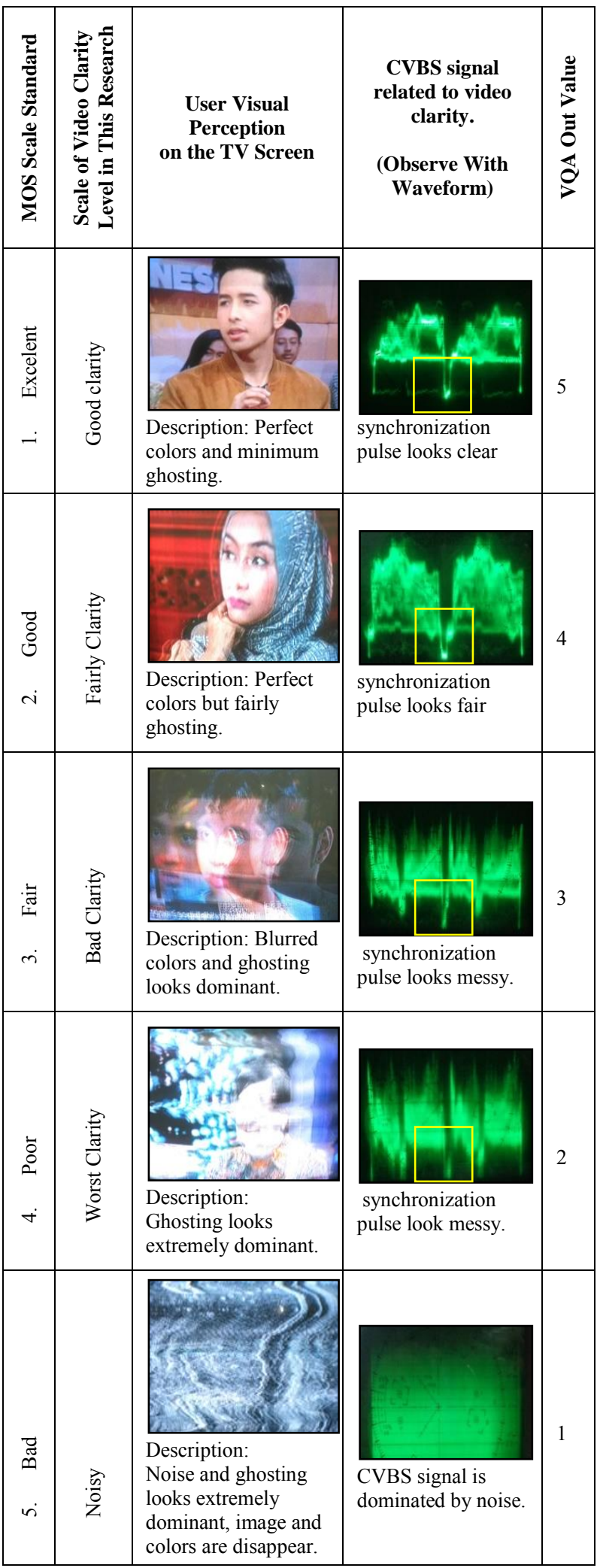

\section{3) Tracking Process and Decision-Making}

Telescopic antennas have a wide variety of angles. To speed up the tracking process, the antenna angle at tracking should be limited. The antenna rod elevation angle is initialized as $\theta_{1}$ for the antenna rods 1 and $\theta_{2}$ for the antenna rod 2 with 3 angle variations $\left(30^{\circ}, 60^{\circ}\right.$ and $90^{\circ}$ ). Meanwhile, the antenna azimuth angle is initialized as $\theta_{3}$ with 7 angle variations $\left(0^{\circ}, 30^{\circ}, 60^{\circ}\right.$, $90^{\circ}, 120^{\circ}, 150^{\circ}$ and $180^{\circ}$ ). Figure 9 shows the antenna angle variations during the tracking process. Thus, the tracking process isi done through 21 steps and its performance is based on a sequence of angle variations that have been determined in Table 2 .

The tracking process is performed in sequence as summarized in Table 2. After the antenna direction is changed due to the rotation of the servo motor, the value on the VQA output is read and stored into the data storage by Arduino UNO in real-time. After the tracking process is done, the system will then take the highest value from data storage. For example, if the highest value is when the tracking process is at step 17 , the servo motor will form an angle $\theta_{1}=\theta_{2}=60^{\circ}$ and $\theta_{3}=$ $150^{\circ}$. Figure 10 shows the flow chart of the decisionmaking process. The decision-making process is written in the listing program of the Arduino UNO microcontroller

\section{RESUlTS AND DISCUSSION}

\section{A. Trial of $R t$ Value Characteristic}

This trial is related to value of $R t$ variable characteristic analysis at some video clarity levels. As discussed in section III.C in particularly at point sub section 2, the value of $R t$ variable is the input of real time VQA. Meanwhile, the real time VQA output is video clarity level information, which is represented by integer values between 1 to 5 . The main purpose of this trial is to get a reference in determining the real-time VQA scale. The method used for the trial process is by setting the antenna manually and then making observations on the values of $R t$ variable. Figure 11 shows the results of $R t$ variable characteristic.

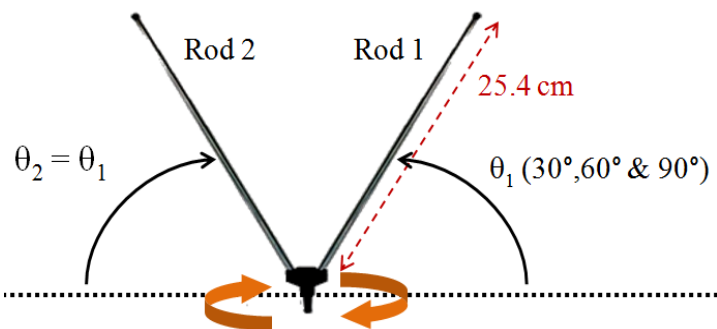

$\theta_{3}\left(0^{\circ}, 30^{\circ}, 60^{\circ}, 90^{\circ}, 120^{\circ}, 150^{\circ} \& 180^{\circ}\right)$

Figure 9. Antenna angle variation during tracking process.

TABLE 2

21 Step Angle Sequence During Tracking Process

\begin{tabular}{|l|c|c|c|}
\hline \multirow{2}{*}{$\boldsymbol{\theta}_{3}$} & \multicolumn{3}{|c|}{$\boldsymbol{\theta}_{\mathbf{1}}$ and $\boldsymbol{\theta}_{\mathbf{2}}$} \\
\cline { 2 - 4 } & $\mathbf{3 0}^{\circ}$ & $\mathbf{6 0}^{\circ}$ & $\mathbf{9 0}^{\circ}$ \\
\hline $\mathbf{0}^{\circ}$ & Step 1 & Step 2 & Step 3 \\
\hline $\mathbf{3 0}^{\circ}$ & Step 6 & Step 5 & Step 4 \\
\hline $\mathbf{6 0}^{\circ}$ & Step 7 & Step 8 & Step 9 \\
\hline $\mathbf{9 0}^{\circ}$ & Step 12 & Step 11 & Step 10 \\
\hline $\mathbf{1 2 0}^{\circ}$ & Step 13 & Step 14 & Step 15 \\
\hline $\mathbf{1 5 0}^{\circ}$ & Step 18 & Step 17 & Step 16 \\
\hline
\end{tabular}




\begin{tabular}{|l|l|l|l|}
\hline $\mathbf{1 8 0}^{\circ}$ & Step 19 & Step 20 & Step 21 \\
\hline
\end{tabular}

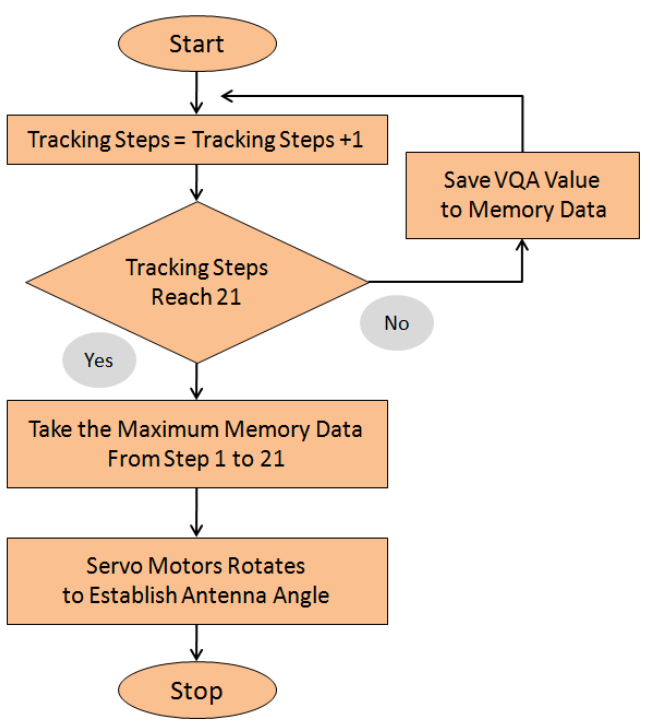

Figure 10. Decision making process

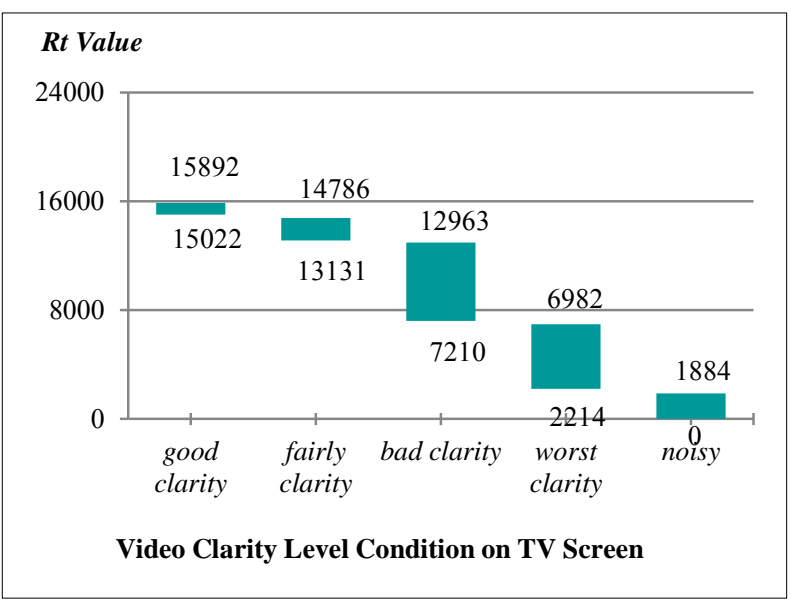

Figure 11. Trial result of $R t$ value characteristic

The trial results show that $R t$ parameter has different values on various video clarity conditions. If the video clarity level becomes better, then the value of $R t$ variable will be closer to a standard value of 16,000 . This is shown when the video clarity level on good clarity condition, that is when the variable $R t$ reaches 15,022 to 15,892

Vice versa, if the video clarity level becomes worse, then the value of $R t$ variable will be closer to zero. This is shown when the video clarity level on the noisy condition, that is when the value of variable $R t$ reaches 0 to 1884 .

Furthermore, the trial result in Figure 11 will be used as a reference in listing program of real-time VQA. If the value of $R t$ variable is rounded, then the program listing on real-time VQA is arranged as in Figure 12.

if $R t \geq 0$ and $R t \leq 1900$ then VQA output $=1$; end; if $R t \geq 2200$ and $R t \leq 7000$ then VQA output $=2$; end;

if $R t \geq 7200$ and $R t \leq 13000$ then VQA output $=3$; end;

if $R t \geq 13100$ and $R t \leq 14800$ then VQA output $=4$; end;

if $R t \geq 15000$ and $R t \leq 16000$ then VQA output $=5$; end;

Figure 12. Listing program on real-time VQA

\section{B. Tracking Performance}

The purpose of this trial is to determine the performance tracking antenna system in general. The trials were conducted indoor with location coordinates at latitude and longitude of $7^{\circ} 19^{\prime} 12.0 \_\mathrm{S} 112^{\circ}$ 43'55.9_E, respectively (i.e. Surabaya city area). In this coordinate, there are $23 \mathrm{TV}$ stations that operate between $9 \mathrm{VHF}$ to $62 \mathrm{UHF}$ channels. However, this trial is restricted to 9 channels that represent the lower channels until the upper channels, i.e. 22 UHF, 24 UHF, 26 UHF, 30 UHF, 36 UHF, 40 UHF, 46 UHF, 58 UHF and 60 UHF. Table 3 shows the results of the tracking performance trial. The number 1 to 5 in the table shows the values of VQA output on 21 tracking steps and the values of VQA output on decision-making moment.

The VQA output value in Table III will certainly have different results if implemented on different region coordinates, different environments or different room structures. However, the focus of this trial is the conformity between the values of VQA output on the decision-making moment with the maximum value of VQA output from 21 tracking steps.

The trial result shows that the tracking antenna system has worked well because at the decision-making moment, the value of VQA output shows maximum value. For example, the trial process on channel $22 \mathrm{UHF}$ shows that from 21 step tracking process, the minimum value of VQA output is 3 ("bad clarity") and the maximum value is 5 ("good clarity"). Then, for the decision-making moment, the value of VQA output can reach a maximum value of 5 ("good clarity"). Another example is the trial process on channel $46 \mathrm{UHF}$, from 21 step tracking process, the minimum value of VQA output is 2 ("worst clarity") and the maximum value is 3 ("bad clarity"). Then, on decision-making moment, the value of VQA output can reach a maximum value of 3 ("bad clarity").

TABLE 3

PERFORMANCE OF TRACKING ANTENNA SYSTEM

\begin{tabular}{|c|l|l|l|l|l|l|l|l|l|}
\hline Tracking & \multicolumn{7}{|c|}{ UHF Chanel } \\
\cline { 2 - 10 } Steps & $\mathbf{2 2}$ & $\mathbf{2 4}$ & $\mathbf{2 6}$ & $\mathbf{3 0}$ & $\mathbf{3 6}$ & $\mathbf{4 0}$ & $\mathbf{4 6}$ & $\mathbf{5 8}$ & $\mathbf{6 0}$ \\
\hline $\mathbf{1}$ & $\mathbf{3}$ & $\mathbf{3}$ & $\mathbf{2}$ & $\mathbf{3}$ & $\mathbf{2}$ & $\mathbf{3}$ & $\mathbf{3}$ & $\mathbf{4}$ & $\mathbf{3}$ \\
\hline $\mathbf{2}$ & $\mathbf{3}$ & $\mathbf{3}$ & $\mathbf{2}$ & $\mathbf{3}$ & $\mathbf{2}$ & $\mathbf{3}$ & $\mathbf{3}$ & $\mathbf{4}$ & $\mathbf{3}$ \\
\hline $\mathbf{3}$ & $\mathbf{3}$ & $\mathbf{3}$ & $\mathbf{2}$ & $\mathbf{3}$ & $\mathbf{2}$ & $\mathbf{3}$ & $\mathbf{3}$ & $\mathbf{3}$ & $\mathbf{3}$ \\
\hline $\mathbf{4}$ & $\mathbf{3}$ & $\mathbf{3}$ & $\mathbf{2}$ & $\mathbf{3}$ & $\mathbf{3}$ & $\mathbf{3}$ & $\mathbf{2}$ & $\mathbf{3}$ & $\mathbf{3}$ \\
\hline $\mathbf{5}$ & $\mathbf{3}$ & $\mathbf{3}$ & $\mathbf{2}$ & $\mathbf{3}$ & $\mathbf{3}$ & $\mathbf{3}$ & $\mathbf{2}$ & $\mathbf{3}$ & $\mathbf{3}$ \\
\hline $\mathbf{6}$ & $\mathbf{3}$ & $\mathbf{3}$ & $\mathbf{3}$ & $\mathbf{4}$ & $\mathbf{3}$ & $\mathbf{4}$ & $\mathbf{2}$ & $\mathbf{3}$ & $\mathbf{3}$ \\
\hline $\mathbf{7}$ & $\mathbf{4}$ & $\mathbf{3}$ & $\mathbf{3}$ & $\mathbf{4}$ & $\mathbf{3}$ & $\mathbf{4}$ & $\mathbf{2}$ & $\mathbf{3}$ & $\mathbf{3}$ \\
\hline $\mathbf{8}$ & $\mathbf{4}$ & $\mathbf{4}$ & $\mathbf{3}$ & $\mathbf{4}$ & $\mathbf{3}$ & $\mathbf{4}$ & $\mathbf{2}$ & $\mathbf{3}$ & $\mathbf{3}$ \\
\hline $\mathbf{9}$ & $\mathbf{4}$ & $\mathbf{4}$ & $\mathbf{3}$ & $\mathbf{5}$ & $\mathbf{4}$ & $\mathbf{4}$ & $\mathbf{2}$ & $\mathbf{3}$ & $\mathbf{3}$ \\
\hline $\mathbf{1 0}$ & $\mathbf{5}$ & $\mathbf{4}$ & $\mathbf{3}$ & $\mathbf{5}$ & $\mathbf{4}$ & $\mathbf{5}$ & $\mathbf{3}$ & $\mathbf{3}$ & $\mathbf{3}$ \\
\hline $\mathbf{1 1}$ & $\mathbf{5}$ & $\mathbf{5}$ & $\mathbf{4}$ & $\mathbf{5}$ & $\mathbf{4}$ & $\mathbf{5}$ & $\mathbf{3}$ & $\mathbf{3}$ & $\mathbf{3}$ \\
\hline $\mathbf{1 2}$ & $\mathbf{5}$ & $\mathbf{5}$ & $\mathbf{4}$ & $\mathbf{5}$ & $\mathbf{3}$ & $\mathbf{5}$ & $\mathbf{2}$ & $\mathbf{3}$ & $\mathbf{3}$ \\
\hline $\mathbf{1 3}$ & $\mathbf{4}$ & $\mathbf{5}$ & $\mathbf{4}$ & $\mathbf{4}$ & $\mathbf{3}$ & $\mathbf{4}$ & $\mathbf{2}$ & $\mathbf{3}$ & $\mathbf{3}$ \\
\hline $\mathbf{1 4}$ & $\mathbf{4}$ & $\mathbf{4}$ & $\mathbf{4}$ & $\mathbf{4}$ & $\mathbf{3}$ & $\mathbf{4}$ & $\mathbf{3}$ & $\mathbf{3}$ & $\mathbf{4}$ \\
\hline $\mathbf{1 5}$ & $\mathbf{4}$ & $\mathbf{4}$ & $\mathbf{3}$ & $\mathbf{4}$ & $\mathbf{2}$ & $\mathbf{3}$ & $\mathbf{3}$ & $\mathbf{3}$ & $\mathbf{4}$ \\
\hline $\mathbf{1 6}$ & $\mathbf{4}$ & $\mathbf{4}$ & $\mathbf{3}$ & $\mathbf{4}$ & $\mathbf{2}$ & $\mathbf{3}$ & $\mathbf{3}$ & $\mathbf{3}$ & $\mathbf{3}$ \\
\hline $\mathbf{1 7}$ & $\mathbf{4}$ & $\mathbf{4}$ & $\mathbf{3}$ & $\mathbf{3}$ & $\mathbf{2}$ & $\mathbf{3}$ & $\mathbf{3}$ & $\mathbf{2}$ & $\mathbf{3}$ \\
\hline $\mathbf{1 8}$ & $\mathbf{4}$ & $\mathbf{3}$ & $\mathbf{3}$ & $\mathbf{3}$ & $\mathbf{2}$ & $\mathbf{3}$ & $\mathbf{2}$ & $\mathbf{2}$ & $\mathbf{3}$ \\
\hline 19 & $\mathbf{4}$ & $\mathbf{3}$ & $\mathbf{2}$ & $\mathbf{3}$ & $\mathbf{2}$ & $\mathbf{3}$ & $\mathbf{2}$ & $\mathbf{2}$ & $\mathbf{3}$ \\
\hline $\mathbf{2 0}$ & $\mathbf{3}$ & $\mathbf{3}$ & $\mathbf{2}$ & $\mathbf{3}$ & $\mathbf{2}$ & $\mathbf{3}$ & $\mathbf{2}$ & $\mathbf{2}$ & $\mathbf{3}$ \\
\hline $\mathbf{2 1}$ & $\mathbf{3}$ & $\mathbf{3}$ & $\mathbf{2}$ & $\mathbf{2}$ & $\mathbf{2}$ & $\mathbf{3}$ & $\mathbf{2}$ & $\mathbf{3}$ & $\mathbf{3}$ \\
\hline $\begin{array}{l}\text { Decision } \\
\text { Making }\end{array}$ & $\mathbf{5}$ & $\mathbf{5}$ & $\mathbf{4}$ & $\mathbf{5}$ & $\mathbf{4}$ & $\mathbf{5}$ & $\mathbf{3}$ & $\mathbf{4}$ & $\mathbf{4}$ \\
Moment & & & & & & & & & \\
\hline Maximum VQA output value & & & & & \\
\hline & & & & & & \\
\hline
\end{tabular}




\section{Tracking Time}

This trial is performed to estimate the tracking time. The trial process is conducted by time measurement when the system is on tracking condition. Stop watch is used for time measurement in this trial. The measurement starts from tracking steps 1 until 21 and ends when the decision-making moment is completed. Figure 13 shows the trial result for tracking time. The trial results show that after 10 trials the minimum (shortest) tracking time is 23.4 seconds and maximum (longest) is 24.6 seconds. Thus, the tracking antenna system takes a long time for tracking process.

For analysis, Table 4 shows the main cause why tracking time takes long time. CVBS signal processing takes 1 second and the tracking steps are 21. Overall, the CVBS signal processing process takes 21 seconds. The decision making moment takes 1 second. The remaining time indicates the time required for the servo motor to rotate the antenna direction.

Based on the percentage of tracking time it can be concluded that tracking time between $85,36 \%$ to $89,74 \%$ dominates the CVBS signal processing time. Therefore, our next research will be focused to find better method, so that the CVBS signals processing can be done for every frame and not every second. Thus, the information regarding video clarity level becomes faster to obtain and the decision-making process also becomes faster.

\section{CONCLUSION}

This research is related to the application of technology for terrestrial analog broadcast TV users. The tracking antenna system is built from servo motor,

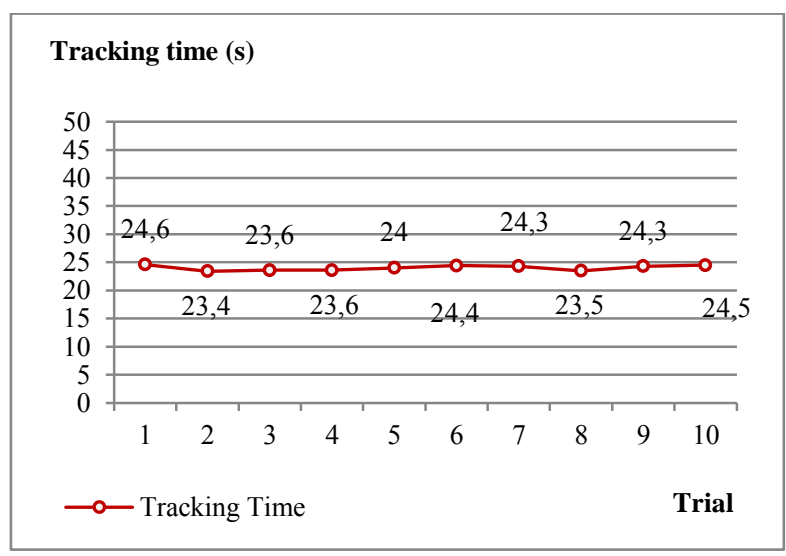

Figure 13. The trial result for tracking time.

TABLE 4

ANALYSIS ON MINIMUM AND MAXIMUM TRACKING

\begin{tabular}{|l|l|l|l|l|}
\hline & \multicolumn{2}{|l|}{$\begin{array}{l}\text { Minimum } \\
\text { Tracking Time } \\
(\mathbf{2 3 . 4} \text { second) }\end{array}$} & \multicolumn{2}{|l|}{$\begin{array}{l}\text { Maximum } \\
\text { Tracking Time } \\
(\mathbf{2 4 , 6} \text { second) }\end{array}$} \\
\cline { 2 - 5 } & second & $\%$ & second & $\%$ \\
\hline $\begin{array}{l}\text { Time for CVBS Signal } \\
\text { Processing }\end{array}$ & 21 & 89.74 & 21 & 85.36 \\
\hline $\begin{array}{l}\text { Time for Decision } \\
\text { Making Process }\end{array}$ & 1 & 4.27 & 1 & 4.07 \\
\hline $\begin{array}{l}\text { Time for The Servo } \\
\text { Motor to Rotate The } \\
\text { Antenna }\end{array}$ & 1.4 & 5.99 & 2.6 & 10.57 \\
\hline
\end{tabular}

telescopic antenna and CVBS signal processing to obtain reference information.

From the trial results, the $R t$ parameter has different values under various video clarity conditions. In other words, the $R t$ parameter can describe the video clarity level on the TV screen.

In general, the tracking antenna system in this work has worked well. This is evidenced from the trial results of the tracking performance. In each trial, the VQA output when decision-making process always pick from maximum value of VQA output. However, the results from the tracking time trial show that the tracking antenna system still needs improvement, especially on the CVBS signal processing.

Further research is needed to find better method, so that the CVBS signals processing can be done for every frame and not every second. This should be conducted so that the tracking antenna system that has been built becomes more reliable and have faster tracking ability.

\section{ACKNOWLEDGEMENT}

The authors acknowledge Direktorat Riset dan Pengabdian Masyarakat (DRPM), Direktorat Jenderal Penguatan Riset dan Pengembangan, Kementerian Riset, Teknologi, dan Pendidikan Tinggi Republik Indonesia (KEMENRISTEKDIKTI) for the Research Funding Year 2017 on research scheme Penelitian Kerjasama Antar Perguruan Tinggi (PEKERTI), that was conducted by Universitas Bhayangkara Surabaya (UBHARA) and Institut Teknologi Sepuluh Nopember (ITS) Surabaya, with contract number 010/SP2H/K2/KM/2017, dated on May 4, 2017. We also acknowledge the ITS Robotics, Information and Communication Technology Center, ITS Telecommunication Network Laboratory and UBHARA Surabaya Electrical Engineering Laboratory.

\section{REFERENCE}

[1] Y. Wahyu, U. Syakirotunnikmah, H. Wijanto, Y. Taryana and A. Setiawan, "Koch fractal antenna at UHF band using EMC feeding for digital terrestrial television applications," Jurnal Elektronika dan Telekomunikasi, vol. 15(1), pp. 1-5, Jun. 2015.

[2] C.-C. Wang, G.-N. Sung, J.-Y. Liao, J. Chang and R. Hu, "Handheld DVB-T digital TV with an automatic antenna selection method for mobile reception," in Digest of Technical Papers. International Conference on Consumer Electronics (ICCE), 2007, pp. 1-2.

[3] C.-C. Wang, T.-J. Lee, H.K. Lo, S.-P. Lin, and R. Hu, "Highsensitivity and high-mobility compact DVB-T receiver for in-car entertainment," IEEE Trans. on Consumer Electronics, vol. 52(1), pp. 21-25, Mar. 2006

[4] H. Miawarni and E. Setijadi, "Antena tracking system based on pulse of synchronization CVBS: design system and analyze," IEEE International Electronics Symposium (IES), 2016, pp. 228 233.

[5] Y. Jiansheng, J. Yingwei and A. Shu, "Application of the improved Kalman filter algorithm to the servo tracking system," International Conference on Quality, Reliability, Risk, Maintenance, and Safety Engineering (ICQR2MSE), 2011, paper 4.28, p. 738.

[6] Y. Tawk, J. Costantine, F. Makhlouf, M. Nassif, L. Geagea and C. Christodoulou, "Wirelessly automated reconfigurable antenna with directional selectivity," IEEE Journal \& Magazine, vol. 5, pp. 802-8011, Jan. 2017.

[7] T. A. White and G. M. Reid, "Quality of PAL Colour Television Pictures Impaired by Random Noise: Stability of Subjective Assessment," IEE Proceedings on Communications, Radar and Signal Processing, 1981, p. 231-236. 
[8] S. Winkler, and P. Mohandas, "The Evolution of Video Quality Measurement: From PSNR to Hybrid Metrics," IEEE Trans. On Broadcasting, vol. 54, No. 3, pp. 660-668. Sept. 2008.

[9] Jones, M. H. Pinson, S. D. Voran, and S. Wolf, An objective video quality assessment system based on human perception, Proc. SPIE, 1993, vol. 1913, pp. 15-26.

[10] H. Miawarni, M. M. Hidayat, S. Sumpeno and E. Setijadi," Real-time video quality assessment based on fuzzy inference system for analog television tracking antenna system," International Seminar on Intelligent Technology and Its Application (ISITIA), 2017, p. 43-48.

[11] H. Miawarni, M. M. Hidayat, S. Sumpeno and E. Setijadi, "Sistem deteksi kejernihan video pada televisi analog berbasis pengolahan sinyal CVBS dan pendekatan MOS-VQS," Seminar Nasional Teknologi dan Informatika (SNATIF), 2017, proc 1, paper 4, p. 27

[12] H. Miawarni, D. E. Setyawan and E. Setijadi,” Desain dan ujicoba synchronization separator sebagai pengkondisi sinyal untuk sistem pendeteksi kejernihan video pada televisi analog," Seminar Nasional TeknologidanInformatika (SNATIF), 2017, proc 1, paper 5, p. 35.

[13] Aplication Note: Video Signal Standards, ST-Microelectronics, 2007.

[14] LM 1881 Video Sync Separator, Texas Instrument, 2003.

[15] Recommendation P.800.1 - Mean Opinion Score (MOS) terminology, ITU-T, 2006. 